\title{
Jane Tutikian entrevista Carina Marques Duarte ${ }^{1}$
}

J.T. Por que a passagem do século XIX para o século XX foi propicia para o surgimento do porque a passagem do século XIX para o século XX foi propícia para o surgimento do Orphismo?

C.M.D. As últimas décadas do século XIX foram marcadas pelo surgimento e pelo aprimoramento de muitas invenções que ocasionaram alterações na vida cotidiana e na percepção de mundo dos indivíduos. Os novos meios de locomoção (balões, aeroplanos, transatlânticos, trens, automóveis, motocicletas, bondes a tração elétrica, elevadores), os novos aparelhos de transmissão (rádio, telégrafo, telefone), as novas técnicas de reprodução de textos, imagens e sons (máquina de escrever, fotografia, cinematógrafo, fonógrafo, gramofone) e as novas descobertas que vinham facilitar o trabalho doméstico, aliados à expansão progressiva da eletricidade, modificaram profundamente o modo de viver, sobretudo nas grandes cidades. As transformações advindas do progresso geraram diferentes reações nos indivíduos: do repúdio ao entusiasmo. Assim, a Paris do final do século XIX estava envolta em dois sentimentos: por um lado, pairava o pessimismo decadentista do fim do século, por outro reinava a euforia da belle époque, a época das boemias literárias, da qual brotam os diversos ismos que caracterizam o desenvolvimento das artes no século XX. Esses movimentos resultaram da exaltação da modernidade, entendida como um conjunto de inovações que tornavam a vida mais fácil. Foram também consequência da automatização de teorias estéticas que já não eram adequadas à representação do novo mundo.

Na França, por volta de 1900, havia uma grande inquietação no meio intelectual, e os escritores já não se contentavam com as soluções simbolistas; arquitetavam novas teorias culturais, redigiam manifestos. Essa movimentação culminou no primeiro manifesto, o futurista, publicado em 1909, nas páginas de Le Figaro. Nesse texto, Marinetti expõe os objetivos da nova estética: cantar, com audácia, coragem e rebeldia, a vida moderna, a velocidade, a máquina, o movimento agressivo e as multidões agitadas pelo trabalho. Em vez de ter os olhos postos no passado e exaltar a imobilidade pensativa, o poeta deveria trabalhar para expressar a nova forma de beleza que constitui os objetos a sua volta. Ainda em 1909, o "Manifesto Futurista" foi traduzido e publicado no Diário dos Açores. Entretanto, não teve repercussão em Portugal. Seria necessário esperar até 1913 para que - graças às novidades trazidas de Paris por Sá-Carneiro e Santa-Rita Pintor (jovens intelectuais portugueses que integrariam a Revista Orpheu) - o movimento futurista tivesse um impacto nas artes portuguesas. Influenciado pelas correntes internacionais e cedendo aos apelos da nova sensibilidade - que, enquanto resultado dos avanços nas ciências e das transformações, exigia um novo código poético - Pessoa, junto com seus companheiros de tertúlia, cria, em 1915, a Revista Orpheu.

\section{J.T. Qual o significado do Ultimatum do Almada Negreiros e o de Campos?}

C.M.D. Publicados em 1917 no único número da revista Portugal Futurista, o "Ultimatum às Gerações Portuguesas”(de Almada) e o "Ultimatum”(de Álvaro de Campos), conforme

1 Doutora em Letras pela UFRGS. Pesquisadora. Autora de Do criador de civilização ao eu-abismo: uma leitura palimpsestuosa do Fausto de Fernando Pessoa (2014) e Quando parte o ultimo comboio? Álvaro de Campos, um seguidor decadente de Walt Whitman e Nietzsche (no prelo). 
sugerem os títulos, dialogam com um dos acontecimentos mais traumáticos da história de Portugal: o ultimato inglês, de 1890, quando a Inglaterra, grande potência da época, exigiu a retirada das tropas portuguesas das colônias africanas. $\mathrm{O}$ ultraje sofrido provocou uma depressão profunda e asseverou o sentimento de decadência. Ao aludirem no título dos seus textos ao memorando inglês, Campos e Almada mobilizam todo o imaginário que o circunda: o da derrocada e da grande humilhação. E, a partir daí, bradam contra a estagnação portuguesa, a mediocridade e a incapacidade criativa. Ambos tecem duras críticas aos valores, às questões políticas e, inclusive, aos poetas, sendo que Almada concentra seu olhar em Portugal enquanto Campos dirige seus "gritos enraivecidos" também a outros países. Em síntese, são textos que denunciam a decadência e, em seguida, propõem uma solução. Para Almada, a superação da decadência passaria obrigatoriamente pela nova geração: "Hoje é a geração portuguesa do século XX quem dispõe de toda a força criadora e construtiva para o nascimento de uma nova pátria inteiramente portuguesa e inteiramente actual prescindindo em absoluto de todas as épocas precedentes". Para Campos, a Grande Hora, ou seja, a ultrapassagem da estagnação e o renascimento português, seria alcançada através da supremacia da obra de Fernando Pessoa.

\section{J.T. O que foi o Orphismo?}

C.M.D. O Orphismo, ou Primeiro Modernismo português, foi um movimento artístico que reuniu nomes como Fernando Pessoa, Mário de Sá-Carneiro, Almada Negreiros, Luis de Montalvor, Ronald de Carvalho, Alfredo Pedro Guisado, Armando Côrtes-Rodrigues, Raul Leal, Santa-Rita Pintor, Eduardo Guimarães, Antônio Ferro e Ângelo de Lima. Teve como principal órgão de divulgação a Revista Orpheu, cujo primeiro número data de 26 de março de 1915. Já na estreia Orpheu escandalizou a sociedade lisboeta (e assim alcançava um dos seus objetivos), o que concorreu para os escritores fossem rotulados de loucos. Por isso, não causa estranheza que, meses mais tarde, o segundo número trouxesse poemas de Ângelo de Lima, um interno do sanatório de Rilhafoles. Mas o objetivo dos orphistas não era apenas chocar a burguesia. Segundo Pessoa, eles pretendiam "criar uma arte cosmopolita no tempo e no espaço", uma arte maximamente despersonalizada, que acumulasse em si todas as partes do mundo, uma arte síntese-soma, que tem a criação dos heterônimos como realização maior. Mais do que deixar um legado literário, o Orphismo pretendia intervir na história da cultura de Portugal, modificar a visão que o seu tempo tinha do próprio passado cultural português.

\section{J.T. Como se dá a passagem de Pessoa do Saudosismo de Teixeira de Pascoaes ao Or- phismo?}

C.M.D. Fernando Pessoa estreou nas letras em 1912, publicando artigos na revista A Águia, órgão de divulgação da Renascença Portuguesa. Naquele momento, Pessoa estava identificado com o ideário saudosista e regeneracionista do grupo de Teixeira de Pascoaes Entretanto, aos poucos, o poeta vai se distanciando da Renascença Portuguesa até a ruptura definitiva, no final de 1914, motivada pela recusa daquela sociedade cultural quanto à publicação do drama estático O Marinheiro. Sabendo da pouca estima que os saudosistas tinham pela sua produção literária e ciente do propósito maior - a renovação do código poético - que o unia a Sá-Carneiro, Pessoa se aproxima cada vez mais do autor de A Confissão de Lúcio, a quem conhecera em 1913, e se afasta do grupo de Teixeira de Pascoaes. 
J. T. Diz-se que a leitura da obra de Max Nordau teve um efeito importante em Fernando Pessoa e por sua vez consequências nos Orphistas...

C.M.D. A ideia de degeneração, trazendo uma visão pessimista do progresso e do futuro da civilização, tomava conta da Europa e influenciava a ciência, a arte e a política em um espaço de tempo que foi de 1850 até 1950. Temia-se a possibilidade de que a Europa estivesse criando uma raça de indivíduos degenerados, propensos a atacar as normas sociais. Partindo do pensamento então corrente, em 1890, Max Nordau, no livro Dégénérescence, buscava explicar toda a arte moderna por meio da indicação das características do degenerado presentes nos artistas. Robert Bréchon sublinha o efeito produzido sobre o jovem Pessoa pela leitura da obra de Max Nordau, que, além de causar-lhe uma forte impressão, o fez perceber o grau de esgotamento a que chegara a cultura no Ocidente no final do século XIX e início do XX. Nordau descrevia os poetas como "degenerados", ameaças para a sociedade. Entre as características do degenerado estavam: incapacidade de agir, gosto pelo devaneio, pelo vago, pelo paradoxo, pela metafísica. Provavelmente Pessoa se identificou com as características do degenerado. O certo é que as transmitiu às suas criações: Álvaro de Campos, Bernardo Soares, Fausto. Convém lembrar, ainda, que as características do degenerado estão presentes também na poesia de Sá-Carneiro, outro inadaptado, a exemplo de Pessoa.

J. T. Qual sua posição sobre os poetas e artistas capitaneados por Fernando Pessoa? Fala-se em geração Orpheu, mas Bréchon um contesta dizendo que era um grupo.

C.M.D. Se considerarmos que o que configura uma geração é a existência de um ideário comum, responsável pela desagregação da geração precedente, preocupações sociais convergentes, anseios históricos semelhantes e orientações estético-literárias semelhantes, concluiremos que Orpheu não era uma geração. Aliás, Antônio Quadros salienta que entre os integrantes de Orpheu, era possível identificar dois grupos: o que, estando ainda muito ligado ao neorromantismo, ao saudosismo e ao neossimbolismo, aparece no movimento pela solidariedade dos cafés lisboetas e o verdadeiramente inovador no conteúdo e na forma. No primeiro, enquadravam-se Luís de Montalvor, Ronald de Carvalho, Alfredo Pedro Guisado, Armando Cortes-Rodrigues, Eduardo Guimarães, Raul Leal e Ângelo de Lima. Ao segundo, o modernista, pertenciam Fernando Pessoa, Sá-Carneiro, Almada Negreiros, Santa-Rita Pintor, Amadeo de Souza-Cardoso, José Pacheco e Antônio Ferro. Ao comentar a disparidade existente entre os membros de Orpheu, Adolfo Casais Monteiro questiona o que fazia um Alfredo Guisado ou um Luís de Montalvor naquele grupo e afirma que o ímpeto revolucionário estava presente apenas em Pessoa, Sá-Carneiro e Almada Negreiros.

J.T. O diálogo entre os Orphistas e as artes é uma realidade. Sá-Carneiro e o surrealismo, por exemplo. Mas mais forte, ainda, a de Caeiro com o primitivismo alemão.

C.M.D. Convém lembrar, em primeiro lugar, a anterioridade da poesia de Sá-Carneiro em relação ao movimento surrealista, À parte isto, são significativos os pontos de contato: devaneio, sobreposição dos sentidos, imaginação desenfreada e associação de ideias inusitadas, opostas à racionalidade. Tais características são marcantes no poema " 16 " , o do braço que se desprende e põem-se a bailar nos salões do vice-rei, causador de enorme escândalo quando da publicação do primeiro número da Orpheu. 


\section{Conexão Letras}

Quanto a Caeiro, é possível identificar analogias entre os seus poemas e o primitivismo alemão, movimento indissociável do grande desenvolvimento da indústria pesada, em curso naquele país nas últimas décadas do século XIX. Em resposta ao progresso industrial, o referido movimento artístico trouxe a valorização do camponês - considerado representativo dos autênticos valores alemães por não ter sido corrompido pelas transformações. $\mathrm{O}$ heterônimo Alberto Caeiro é o homem do campo e atribui à vida pastoril beleza, harmonia e equilíbrio, que, segundo ele, estão ausentes nas cidades.

\section{J.T. E o diálogo de Bernardo Soares com o Fausto?}

C.M.D. Bernardo Soares (semi-heterônimo) e Fausto (protagonista do poema dramático Fausto: tragédia subjectiva) são decadentes. Ambos não aceitam a existência de Deus como última verdade e nisso dialogam com Zaratustra. Há, entretanto, uma distância considerável entre a posição das criações de Pessoa e a da personagem conceitual do filósofo. A morte de Deus, em Nietzsche, tem um sentido positivo: Deus morre para que viva o Super-homem, ou seja, para que o indivíduo, liberto dos limites, possa desenvolver as suas melhores possibilidades. Para Fausto e Bernardo Soares, a ausência da crença está longe de ter uma significação positiva, haja vista que tampouco acreditam no homem. Por isso, ficam, como admite Soares, na "orla das gentes, naquela distância de tudo a que comumente se chama a Decadência. A Decadência é a perda total da inconsciência: porque a inconsciência é o fundamento da vida". Inconsciência se afina com inocência, crença, paz e felicidade, ao passo que a consciência produz a dúvida, a contemplação, a inatividade, o tédio e o desespero. Fausto e Bernardo Soares, homens ultraconscientes, se tornam prisioneiros do pensamento e da contemplação da realidade, abdicando de toda relação concreta com os entes. Não podendo penetrar na realidade, passam a residir no labirinto, o que equivale a estar perdido de si e do mundo. Por isso, com uma angústia imensa, retornam sempre às mesmas questões. Além disso, o temperamento inquiridor de ambos os leva à convicção de que não nasceram para a atividade prática. Fausto não se concebe agindo e Bernardo Soares se considera um indivíduo inerte, falho de gestos e atos. Entretanto, a inação, característica destas duas criações de Fernando Pessoa, como demonstra o testemunho de Bernardo Soares, provém da excessiva lucidez: "Só aos poetas e aos filósofos compete a visão prática do mundo, porque só a estes é dado não ter ilusões. Ver claro é não agir". Presas da inação, mas jamais do imobilismo do pensamento, o semi-heterônimo e a personagem trágica conservam aquele que, para ambos, é o alimento da alma: a dúvida.

\section{J.T. O que dizer de Campos e Withman?}

C.M.D. Há um diálogo profícuo entre o Campos eufórico - cantor da face multímoda da vida moderna - e o autor de Leaves of Grass. Em Whitman, o heterônimo buscou, além do verso livre, as anáforas, as enumerações, as repetições, as justaposições, os oxímoros, o rítmo, a retórica, a atitude lírica e os temas. A exemplo de Whitman, Campos compõem seus versos com uma diversidade de quadros e personagens, focaliza a movimentação urbana e deseja fundir-se com a realidade. Todavia, a integração completa, alcançada pelo bardo norte-americano, para Campos, não é possível. Cabe lembrar as palavras de Fernando Pessoa, quando afirma que, apesar de Campos ser o heterônimo que mais se 
assemelha a Whitman, não possui nada da camaradagem do norte-americano; antes, está sempre afastado da multidão "[...] e quando sente com ela é bem clara e confessadamente para agradar a si mesmo e conceder-se sensações brutais".

Da poesia de Walt Whitman - espaço onde figura uma diversidade de temas e personagens - emerge um protagonismo: o do poeta. Assim ocorre também nos poemas do poeta-engenheiro. No centro da representação, figura a imagem do próprio Campos. Tal como o autor de Leaves of Grass, se declara divino e, portanto, apto a entoar o canto à diversidade, à liberdade e à democracia, Campos também afirma-se Deus. Entretanto, o caráter divino do heterônimo autoriza-o a rejeitar a conjuntura em que está inserido.

O perturbador contato com Leaves of Grass conduziu Pessoa à criação da versão portuguesa e modernista para a consubstanciação whitmaniana com a realidade: o Sensacionismo. Um dos poemas nos quais esta vanguarda se expressa é "Saudação a Walt Whitman", texto que testemunha o fascínio exercido pelo norte-americano sobre Pessoa. A relação intertextual entre a "Saudação" e "Song of myself" é flagrante. Apto a absorver alteridades, a partir das quais se constitui, em "Song of myself", o poeta pode sentir tudo e estar em todos os lugares. Esse é um viés do rompimento de barreiras executado por Whitman que contribui para que o poeta tenha confiança na sua expressão poética e sintase um guia. Além disso, o eu poético assume o discurso de líder, considera-se imortal e, mesmo em face da possibilidade de não reconhecimento, se mostra tranquilo. Tal postura diverge da adotada por Álvaro de Campos. Este, ao denominar-se o "espírito que dá a vida", confere a si uma posição de destaque e se reclama divino, porém, quando pondera que a permanência dos versos dependerá dos leitores, fica deprimido, e a depressão o acompanha na maioria dos fragmentos do poema.

Desse modo, percebemos que, em Campos, o afã de estar em todas as coisas e a exaltação são apenas possibilidades de fuga, fuga da introspecção, do tédio, da melancolia, do pensamento. O ser tudo de todas as maneiras surge como uma tábua de salvação, sem a qual Campos sucumbiria ao tédio herdado do Decadentismo.

Importa salientar que Whitman sentiu a influência do acelerado desenvolvimento material do seu país e se apaixonou pelas características de país altamente civilizado. O progresso, a construção da primeira estrada de ferro transcontinental, a colocação, no fundo do oceano, do primeiro cabo telegráfico submarino e a construção do Canal de Suez o inspiraram. Ademais, quando publicou a primeira edição de Leaves of Grass, em 1855, a crença do individualismo norte-americano aumentava. Consequentemente, nos seus poemas há um grande otimismo, otimismo imposssível para o Álvaro de Campos de um país atrasado e que ainda elaborava o trauma do ultimato.

\section{J.T. E os brasileiros do Orphismo? Nada mais interessante do que pensar em Eduardo Guimarães, um simbolista arraigado.}

C.M.D. Eduardo Guimarães (que junto com Cruz e Souza e Alphonsus de Guimarães forma a chamada tríade do Simbolismo brasileiro) e Ronald de Carvalho pertenciam à "ala simbolista" da Orpheu. Ronald de Carvalho, amigo de Montalvor (diretor português da Orpheu), teria sido o primeiro a ter a ideia de criar a revista e foi nomeado co-diretor brasileiro da publicação.

A variedade de pensamentos e interesses encontrados nos integrantes de Orpheu é significativa. Entretanto, foi a vontade de criar uma revista nova que uniu temperamentos e estilos tão distintos. 


\section{Conexão Letras}

J.T. A maior contribuição do Orphismo ao Modernismo português foi mesmo o Sensacionismo? O que era o Sensacionismo?

C.M.D. O Sensacionismo foi um movimento de vanguarda português criado por Fernando Pessoa. De acordo com o poeta, o movimento descende do Simbolismo francês, do panteísmo transcendentalista português, do Futurismo e do Cubismo. Não possui um caráter excludente; ao contrário, pretende ser uma síntese de todas as correntes anteriores. Por isso, Pessoa dizia: " a uma arte assim cosmopolita, assim universal, assim sintética, é evidente que nenhuma disciplina pode ser imposta, que não a de sentir tudo de todas as maneiras, de sintetizar tudo, de se esforçar por de tal modo expressar-se que dentro de uma antologia da arte sensacionista esteja tudo quanto de essencial produziram o Egito, a Grécia, Roma, a Renascença e a nossa época. A arte, em vez de ter regras como as artes do passado, passa a ter só uma regra - ser a síntese de tudo". O Sensacionismo estava assentado sobre os princípios de que todo objeto é uma sensação nossa e que toda arte é a transformação de uma sensação em objeto. A sensação, ao ser convertida em objeto (poema), se torna uma sensação para os outros. Sendo assim, o ideal era sentir tudo de todas as maneiras, pois, desse modo, mais sensações seriam geradas.

Se tivermos em conta que o Sensacionismo surgiu com a criação dos heterônimos e que a referida vanguarda e a heteronímia se integram no projeto pessoano de abarcar, através da poesia, a totalidade do real, podemos dizer, sim, que a grande contribuição do Orphismo foi o Sensacionismo. 